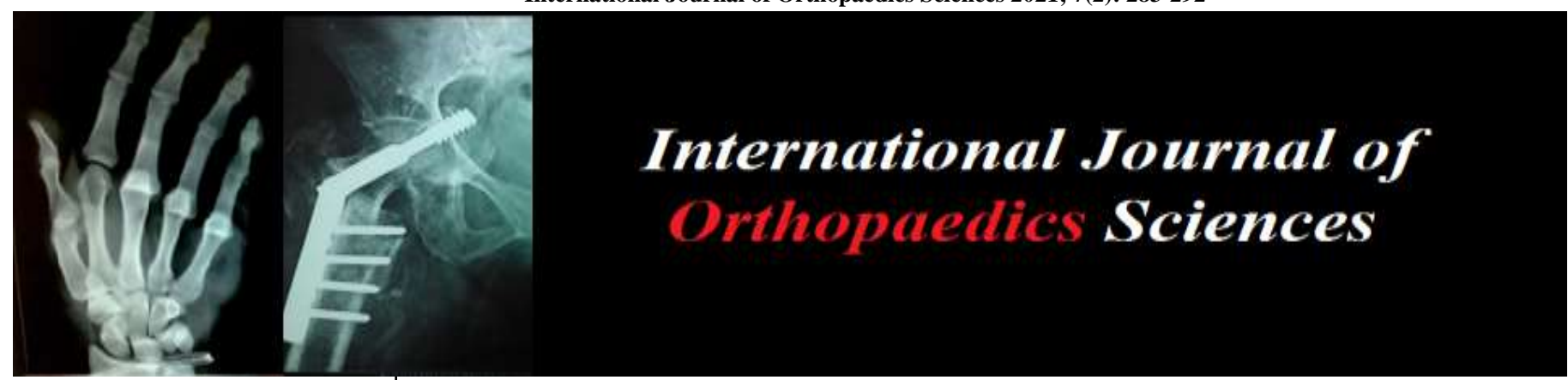

E-ISSN: 2395-1958

P-ISSN: 2706-6630

IJOS 2021; 7(2): 283-292

(C) 2021 IJOS

www.orthopaper.com

Received: 13-02-2021

Accepted: 22-03-2021

\section{Dr. Satheesh GS}

Department of Orthopaedics,

Adichunchanagiri Institute of

Medical Sciences, B.G. Nagara

Mandya, Karnataka, India

Dr. Gopalakrishna Pattar

Department of Orthopaedics,

Adichunchanagiri Institute of

Medical Sciences, B.G. Nagara,

Mandya, Karnataka, India

Dr. BG Sagar

Department of Orthopaedics, Adichunchanagiri Institute of Medical Sciences, B.G. Nagara Mandya, Karnataka, India
Corresponding Author: Dr. Satheesh GS

Department of Orthopaedics, Adichunchanagiri Institute of Medical Sciences, B.G. Nagara, Mandya, Karnataka, India

\title{
A prospective study of surgical management of Schatzker Type V (Bicondylar) \& Type Vi tibial plateau fracture by dual plating
}

\section{Dr. Satheesh GS, Dr. Gopalakrishna Pattar and Dr. BG Sagar}

DOI: https://doi.org/10.22271/ortho.2021.v7.i2d.2644

Abstract

AIM: To assess the clinical and functional outcome of surgically treated proximal tibial fractures with dual plating at AIMS, B.G. Nagara during August 2018 to December 2020.

Objectives

1. To assess the articular surface anatomical reduction of PROXIMAL tibia perfectly by operative treatment with internal fixation.

2. To assess the union of fractures radiologically after internal fixation with dual plates

3. To assess the clinical outcome associated with this treatment modality

a. $\quad$ Range of movements of knee joint

b. Relief of pain for the patient

c. Return to routine daily activities and work

Materials and Methods: Total number of cases studied were 20.

- Inclusion criteria: All patients who are skeletally mature with proximal tibia fracture Schatzker type V and VI (>18 years), AO Muller type 41-C1, 41-C2, 41-C3, Gustilo-Anderson type I and II compound proximal tibial fracture.

- Exclusion Criteria: Patients with Gustilo-Anderson Type 3 compound tibial plateau fractures, Children with proximal tibial fractures with intact growth plate, patients with pathological proximal tibial fractures apart from osteoporosis.

Observation and Results: Our study used Honkonen Jarvinen Criteria for radiological, functional, clinical outcome which showed excellent to good result. Our study reported Honkonen Jarvinen Clinical outcome to be $85 \%$ excellent, $12 \%$ good and $2 \%$ fair. The functional outcome was $80 \%$ excellent, $14 \%$ good, $4 \%$ fair and $2 \%$ poor. The Radiological outcome showed $79 \%$ excellent, $15 \%$ good, $0.70 \%$ fair results.

Conclusion: From this study we conclude that, proximal tibial fractures (Schatzker type V and type VI) managed surgically with dual plating gives excellent anatomic reduction, accurate axial and articular alignment with rigid internal fixation by dual locking plate, achieving a stable and better functional knee joint.

Keywords: Schatzker type V and VI, dual plating, Honkonen Jarvinen criteria

\section{Introduction}

Proximal tibia with tibial condyles and their articular surface forms major part of the knee joint, which plays an important role in weight transmission and mobility ${ }^{[1]}$. The proximal tibia fractures account for $1 \%$ of all the fractures ${ }^{[1]}$, with increase in high velocity road traffic accidents, there is increase in the incidence of proximal tibia fractures ${ }^{[1]}$. The goal of treating these bicondylar tibial plateau fractures is to bring back the functional mobility to pre injury status. Hence near anatomical reduction of articular surface, maintainance of mechanical axis and anatomical alignment has to be achieved with stable fixation and early mobilization ${ }^{[2,3]}$. If these high velocity intra/peri articular fractures are not treated properly there will be high degree incidences of complications like malunion, non-union, peri-operative infections, varus collapse of the medial condyle, ligamentous instability, malalignment of the axis, articular incongruity leading to post traumatic arthritis.

The advantages in treatment of these proximal tibial fractures including bicondylar fractures with dual plating over other types of fixation are: fixation involve, 
1. Posteromedial plate can be used to fix the coronal split of the medial condyle.

2. Articular surface can be reconstructed better.

3. Better distribution of forces along the axis of the bone

4. Better load sharing capability with dual plates compared to single lateral plate alone

5. This Fixation with dual plates help to prevent the medial condyle collapse

6. Early knee joint mobilization and rehabilitation.

In a nut shell, this dual plating technique allows for anatomic joint reduction, adequate fixation, maintainance of alignment, and early rehabilitation to achieve better functional outcome.

\section{Materials and Methods}

This prospective study conducted at AIMS, B G Nagara from August 2018 to december 2020 with follow up of 9 months, total no cases are 15. All the cases were diagnosed with Schatzker type V and VI by standard AP and lateral view Xrays were taken in to study, CT scan was done to know the exact pattern of fracture and fragments.

\section{Inclusion criteria}

1. All patients who are skeletally mature with proximal tibia fracture Schatzker type V and VI (>18 years)

2. AO type 41-C1, 41-C2,41-C3

3. GA type I and II open proximal tibial fractures

4. Patients willing to take part in our study.

\section{Exclusion criteria}

a. Tibial plateau unicondylar fractures \{type I, II, III, IV) type of Schatzker classification

b. Patients with Gustilo-Anderson Type 3 open proximal tibial fractures.

c. Patients who are Skeletally immature.

d. Patients with pathological proximal tibial fractures apart from osteoporosis.

e. Delayed presentation of fractures more than 3 weeks.

On admission of the patient, demographic data was collected and a thorough history was taken to assess the mode of injury and associated comorbidities. General, systematic and local examination were done.

Physician fitness taken before operating after all routine blood investigations, ECG, chest X-ray, etc., consent obtained from the patients and their attenders.

\section{Pre-operative planning}

Patients were received in the emergency room and initially stabilised hemodynamically. Then injectable analgesics were given. The injured lower limb was immobilised in an Above Knee Splint and Anteroposterior, Lateral, Oblique X-rays (if required) were taken. CT scan was taken to assess the fracture pattern and fragments. If associated soft tissue injury, if required calcaneal pin traction was put. Adequate time given for the soft tissue to heal ranging from 4-14 days. We waited for the swelling to decrease, for the fracture blisters to settle and till the skin wrinkles appeared. Mean while, appropriate antibiotics, analgesics were given. Selection of implants, appropriate sizes of LCPs, proximal tibial plates (postero medial and lateral plates) with screws was done. Pre anesthetic evaluation and pre anesthetic medications were given and parts preparation done. Adequate amount of iso compatible blood arranged.

\section{Timing of surgery}

The average period from day of injury to surgery was 5.3 days with a range between 3 to 9 days.

\section{Surgical procedure}

Under aseptic conditions and Preoperative IV antibiotics Inj cefeperazone $1 \mathrm{~g}+$ sulbactum $500 \mathrm{mg}$ were given after test dose as prophylaxis. The patient placed in supine position with a folded pillow under affected knee and a sand bag under ipsilateral gluteal region for anterolateral approach and a sand bag under contralateral hip with figure of four position of ipsilateral leg for posteromedial approach. First indirect fracture reduction was achieved with longitudinal traction, under $\mathrm{C}$-arm guidance. Percutaneous $\mathrm{K}$ wires were used to hold the fragments in reduction. We typically fix medial tibial condyle first. If medial condyle is comminuted we fix lateral condyle to achieve length.

Through posteromedial approach to proximal tibia with approximately $8 \mathrm{~cm}$ incision over posteromedial border of proximal tibia. After opening subcutaneous fat, long saphenous vein and saphenous nerve identified and preserved. Pesanserinus expansions identified. Tibia was approached after incising pes anserinus longitudinally in the line of skin incision. The gastronemics muscle was gently freed from posteromedial surface by blunt dissection.

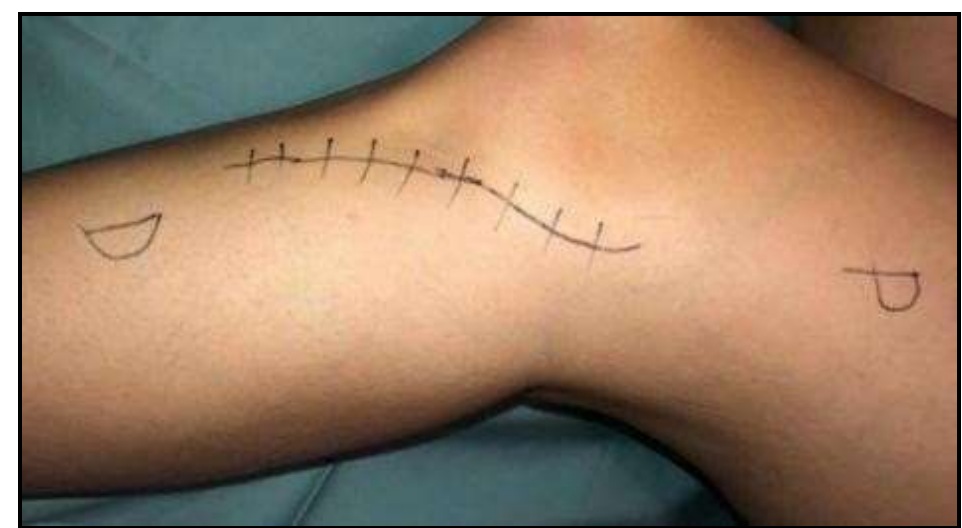

Anterolateral incision (Lazy's')

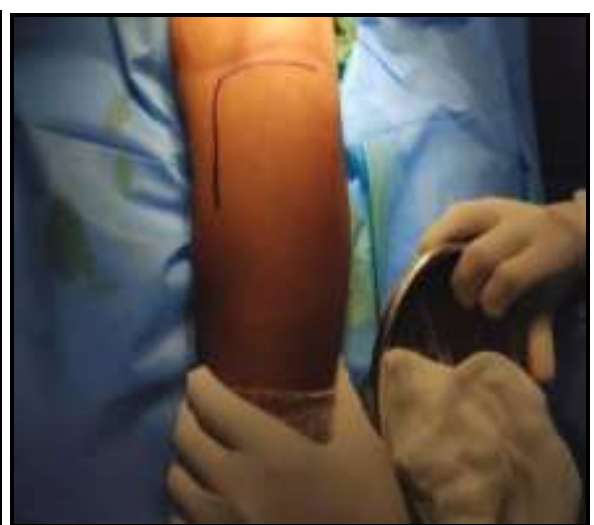

Posteromedial incision
The fracture fragments were visualized and were reduced under $\mathrm{c}$ arm guidance. If there was articular depression a bone punch was used to elevate the depressed portion and the void was filled with bone graft. The reduced fragments were fixed with $3.5 \mathrm{~mm}$ proximal tibia posterior medial locking plate. The lateral condyle fracture was approached antero laterally. "S" shaped incision was made starting $5 \mathrm{~cm}$ proximal to joint line curving the incision anteriorly over Gerdy's tubercle and 
extend it distally $1 \mathrm{~cm}$ lateral to anterior border of tibia. Joint capsule was incised. Tibialis anterior was elevated by blunt dissection. Under $\mathrm{C}$ arm guidance, fracture reduced and fixed with Proximal Tibia Lateral Locking Compression Plate. If depression was present in articular surface, elevation followed
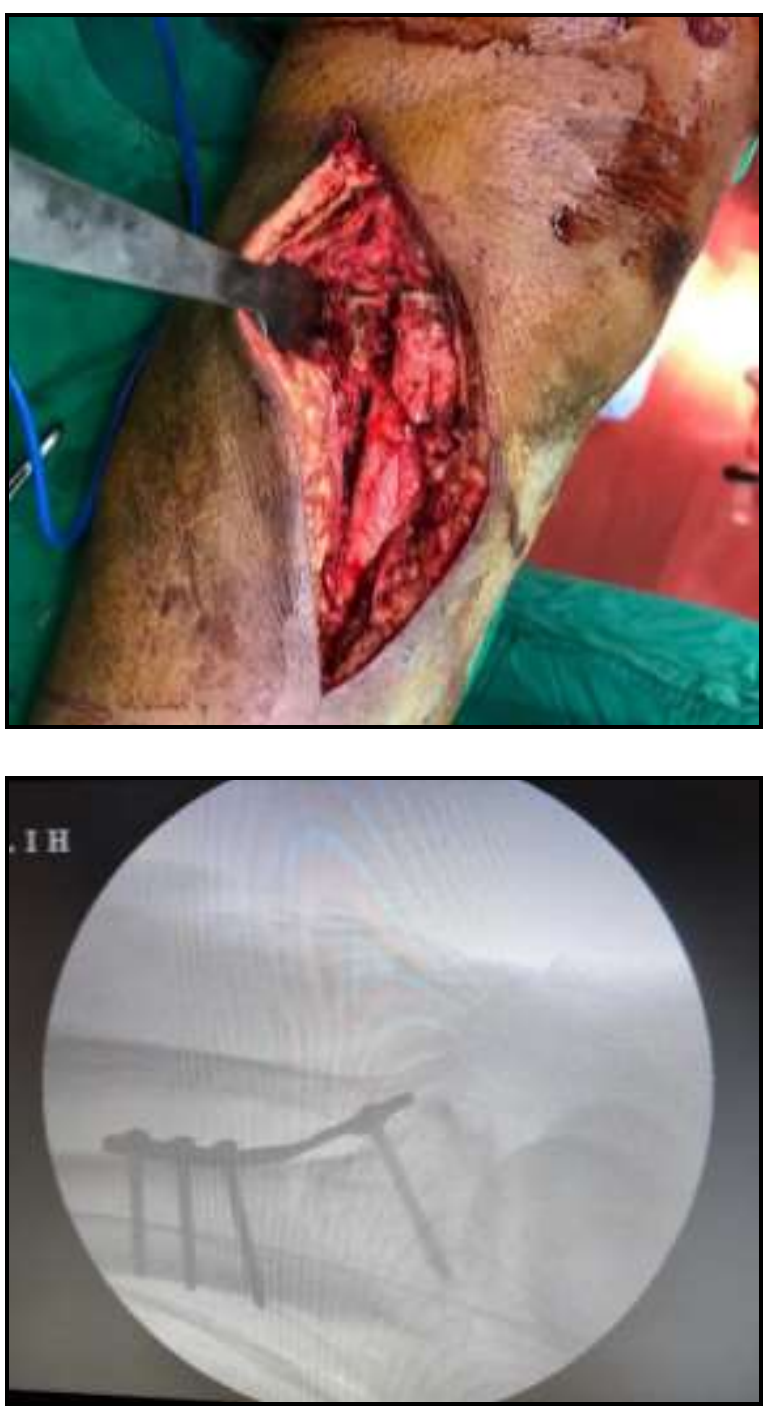

$\mathrm{C}$ arm pic of posteromedial plating

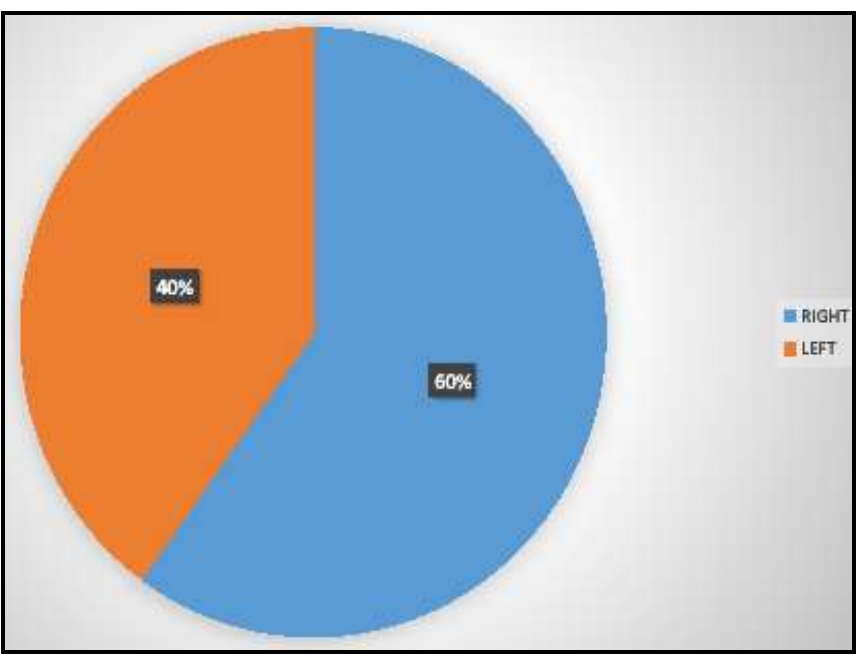

Graph 1: Laterality Graph by bone grafting was done if necessary. A drain was kept for both wounds with help of Y connector.

\section{Intra operative pictures}
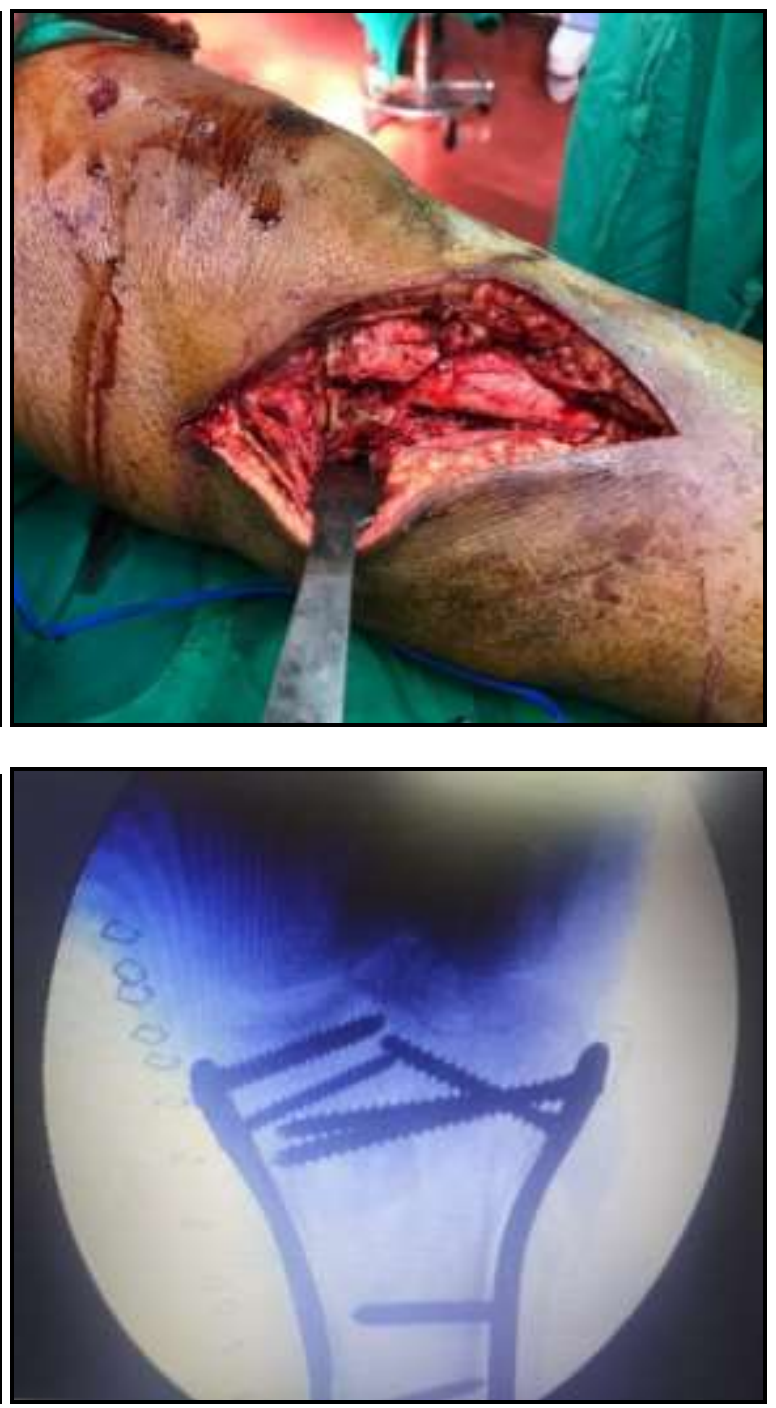

$\mathrm{C}$ arm pics dual plating

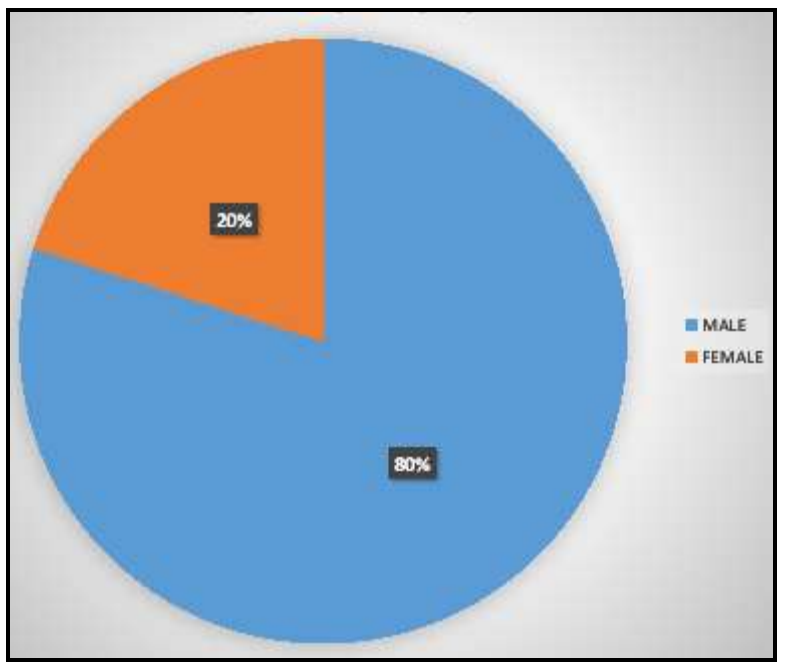

Graph 2: Sex Distribution GRAPH 


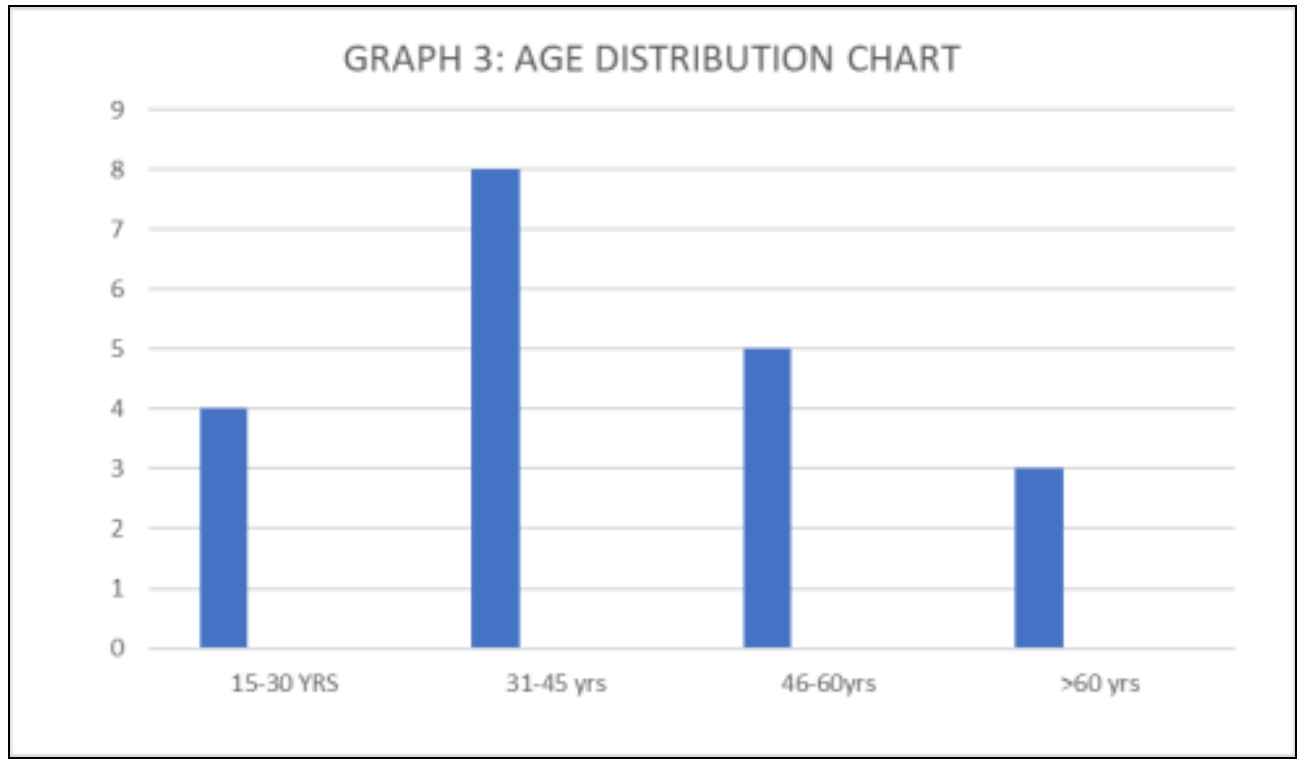

Graph 3: Age Distribution Chart

Table 1: Shows in RTA and Fall from Height

\begin{tabular}{|c|c|c|}
\hline Mode of injury & RTA & Fall from height \\
\hline $15-30$ & 4 & 0 \\
\hline $31-45$ & 6 & 2 \\
\hline $46-60$ & 4 & 1 \\
\hline$>60$ & 2 & 1 \\
\hline Total & 16 & 4 \\
\hline
\end{tabular}

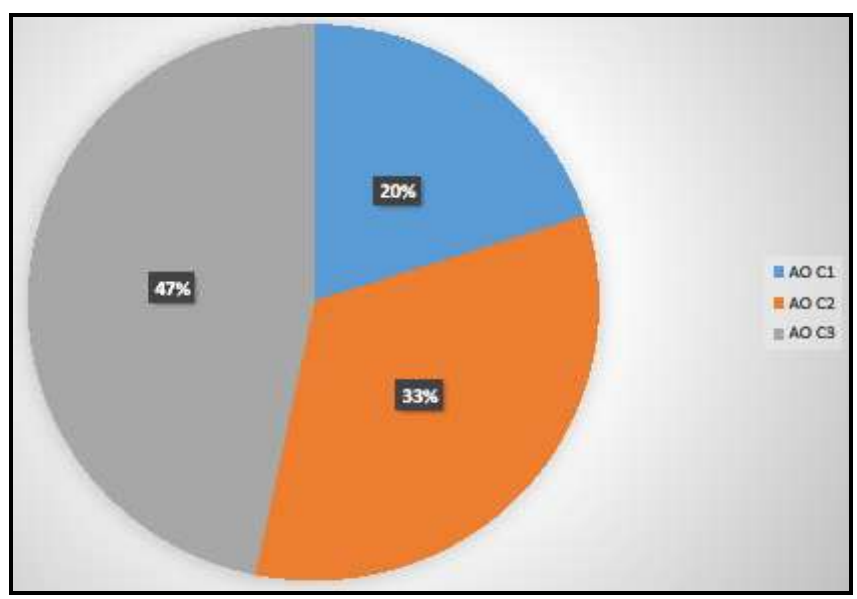

Graph 4: According to Ao Classification

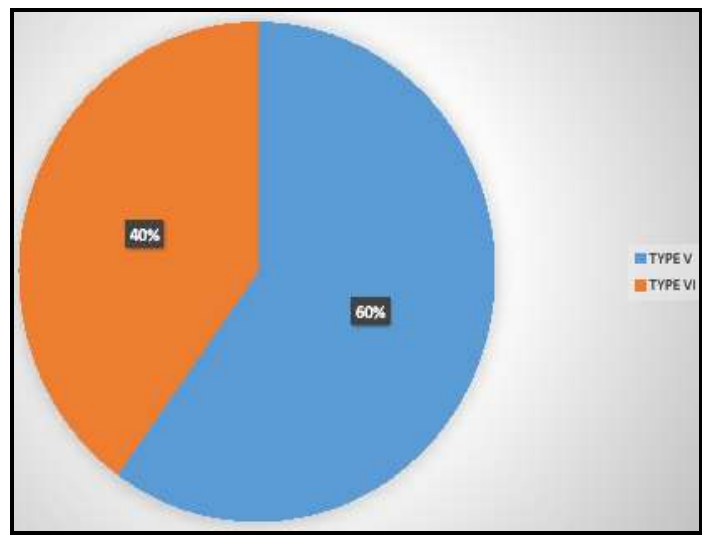

Graph 5: According To Schatzker Classification

\section{Complications}

- Out of 20 operated patients, 4 had post operative complications, out of which 2 patients had knee stiffness, which was overcome with strict physiotherapy.

- One patient had superficial wound infection which subsided with wound debridement and i.v. antibiotics according to culture and sensitivity.

One patient had skin necrosis for which split skin grafting was done. It improved with regular saline dressing.

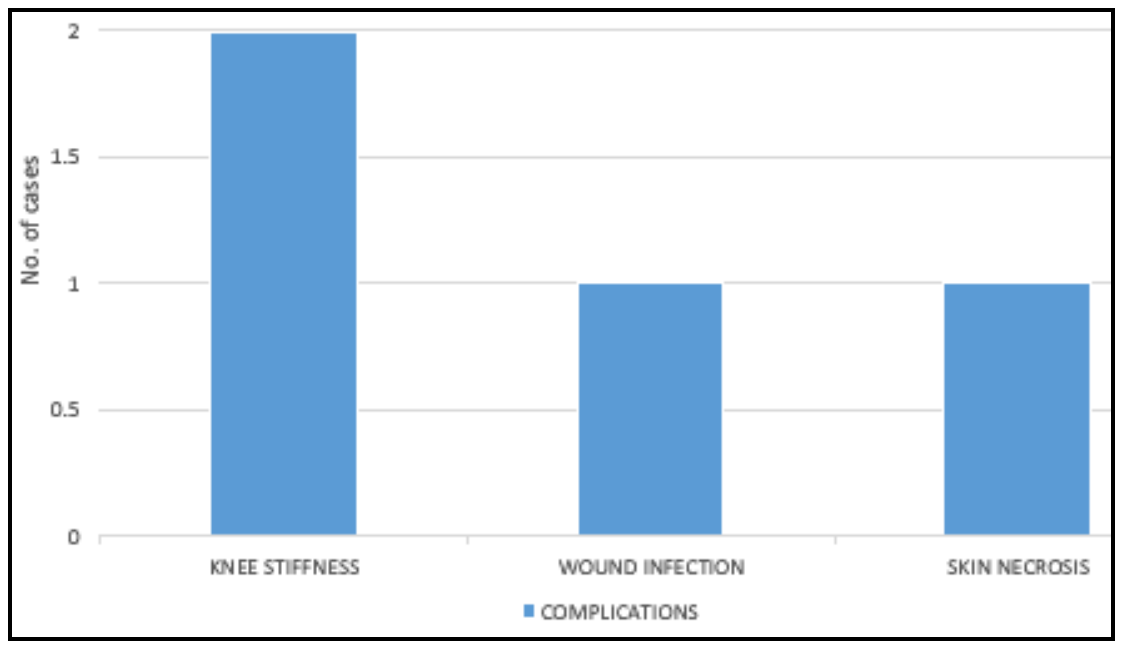



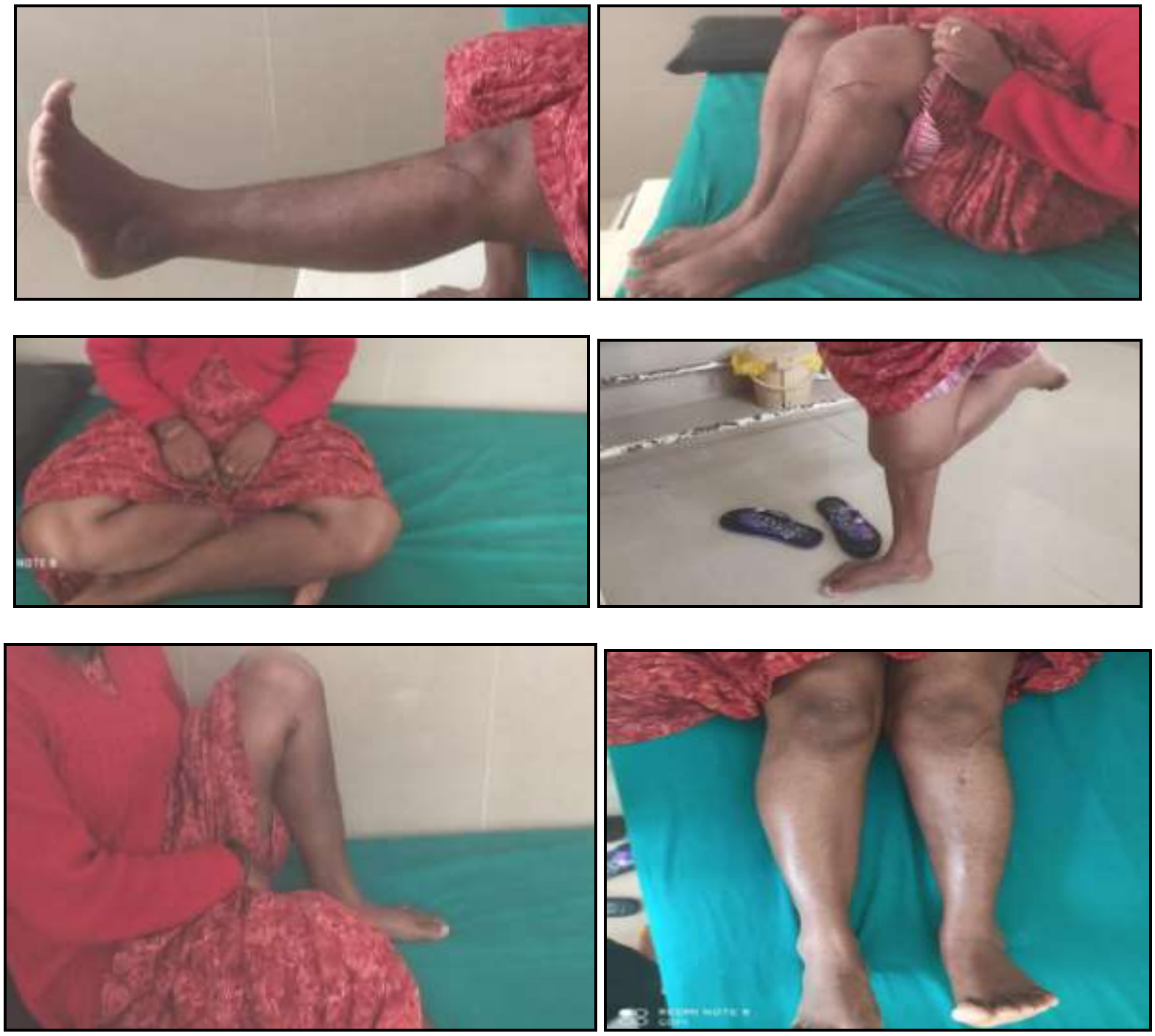
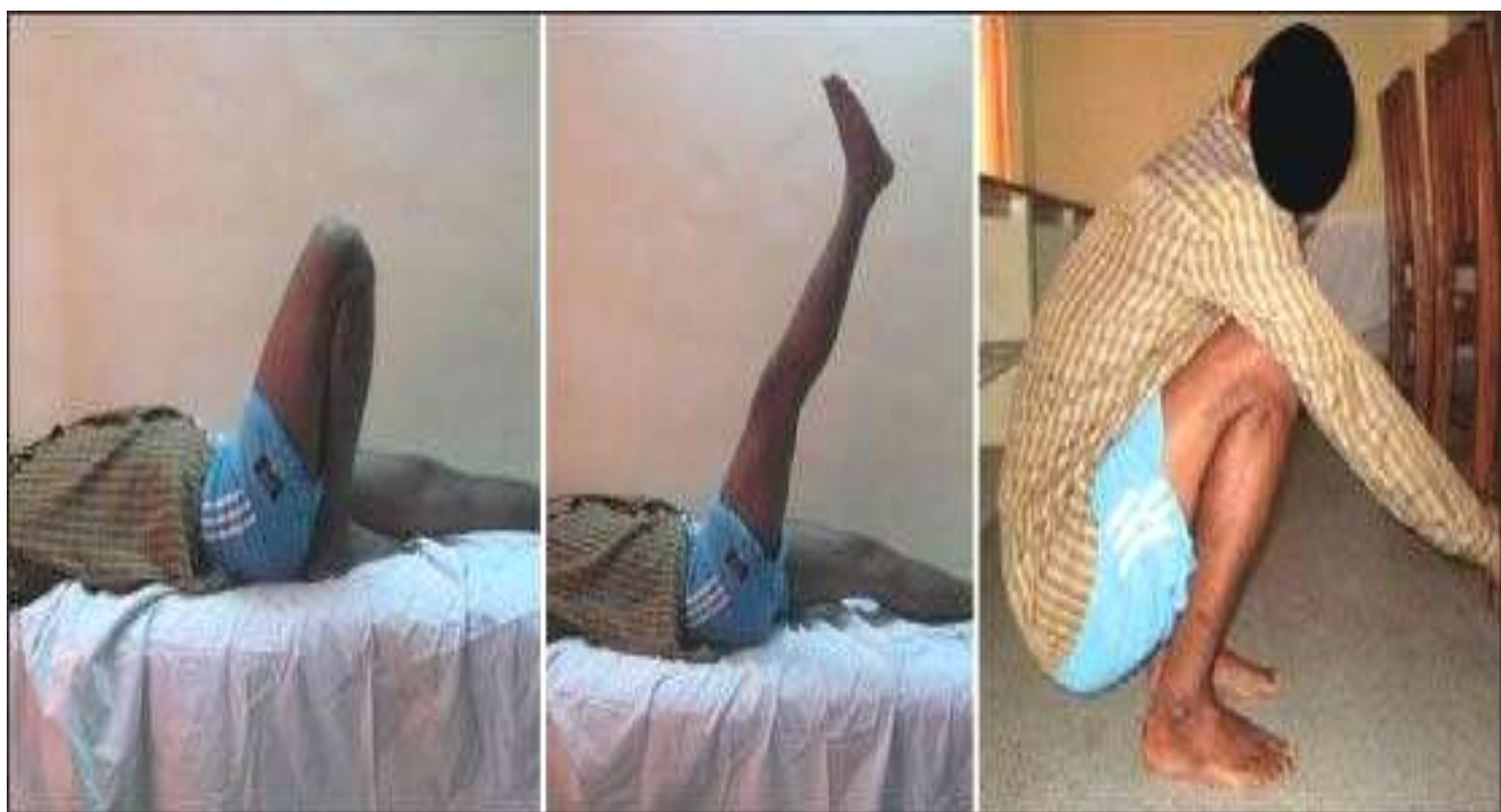

Functional outcomes of all patients were assessed clinically be measuring ROM, laxity on stress tests, Oxford knee score, and wound complications and radiologically by looking for signs of union and malalignment or secondary loss of reduction. Consolidation of atleast three cortices was considered as union and no signs of healing for 6 consecutive months were considered to be nonunion. Malreduction or malalignment is defined as intrarticular step-off over $2 \mathrm{~mm}$ or angulation more than $5^{\circ}$ in either frontal or sagittal plane, respectively. Malalignment was considered as abnormal and was measured using method described by Paley etal.

\section{Results}

Twenty patients met the inclusion criteria for our study and 
were operated with dual plating technique through two incision approach using locking or buttress plate after adequate healing of soft tissues. Road traffic accident was the most common mode of injury and all cases belong to high velocity trauma. Mean age group of patient was 36 yrs with range from 24yrs to 58yrs, including 16 males and 4 females. All patients belong to Shazker Type V and VI classification along with coronal fracture and dislocation patterns.

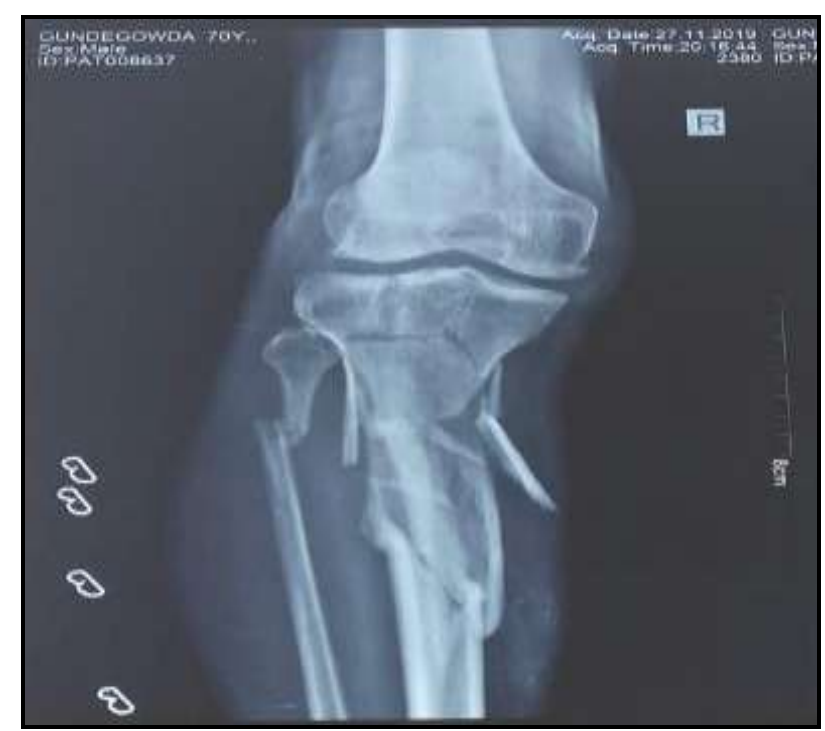

Pre-operative

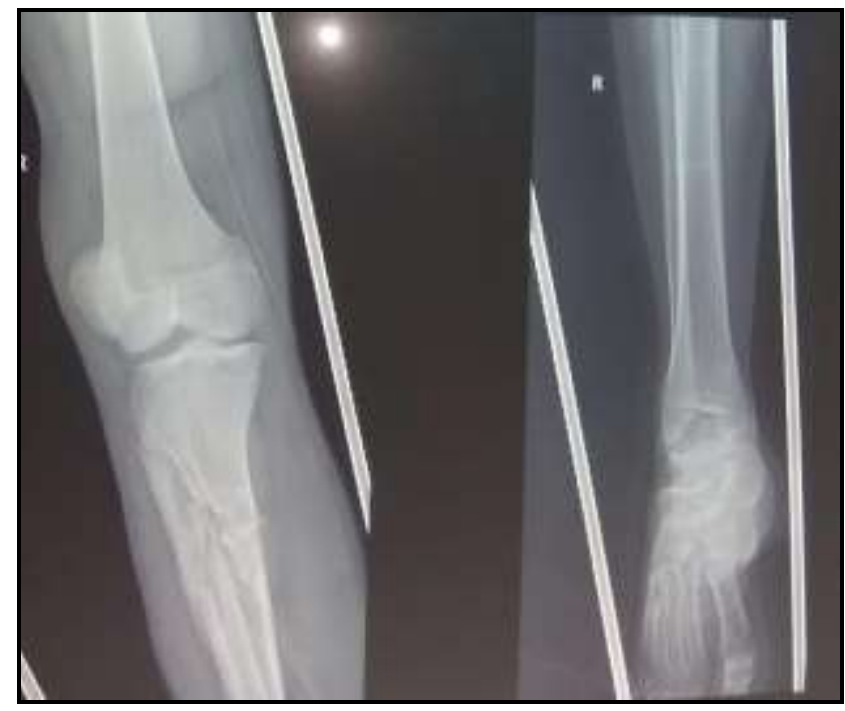

Pre-operative

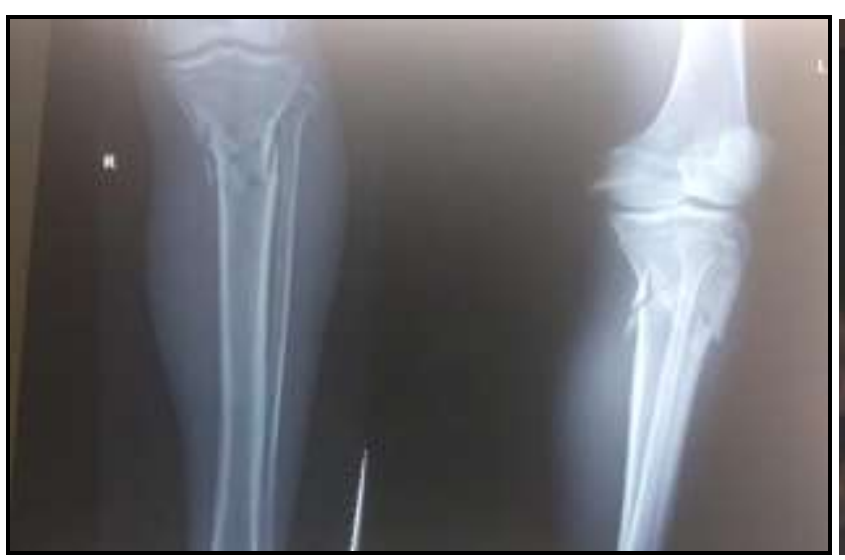

Pre-operative

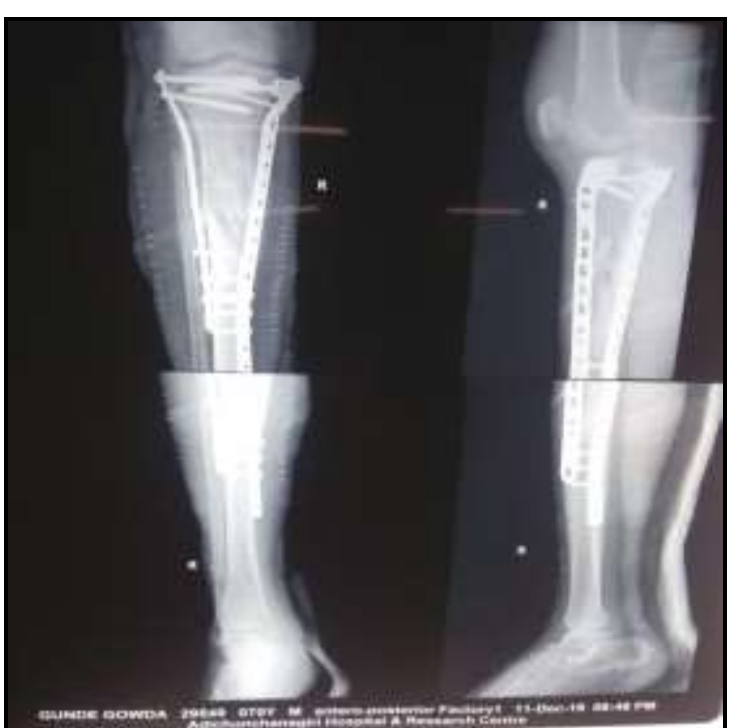

Post-operative

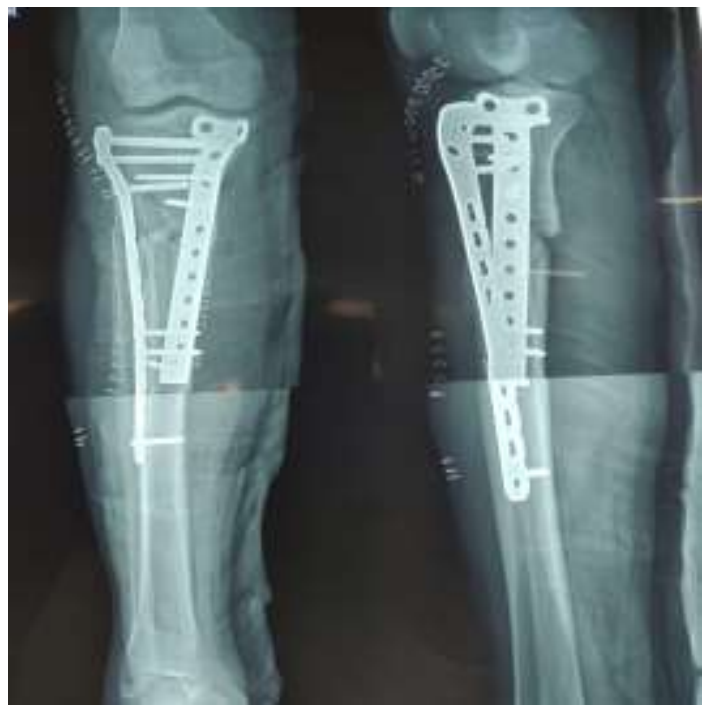

Post-operative

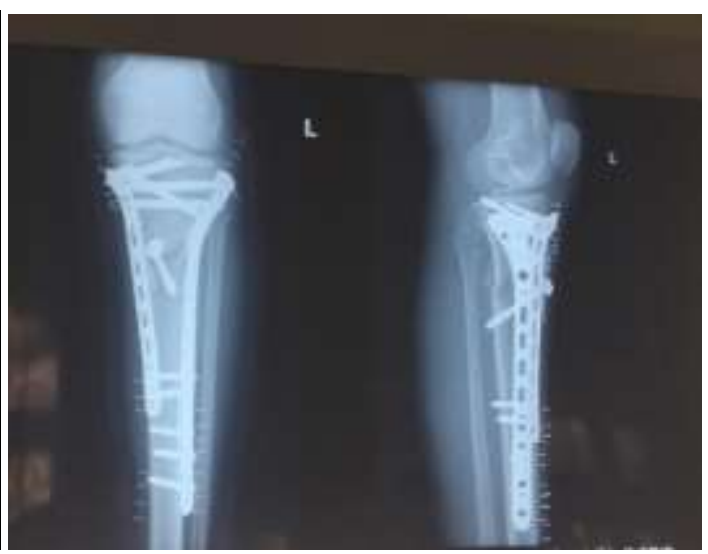

Post-operative 


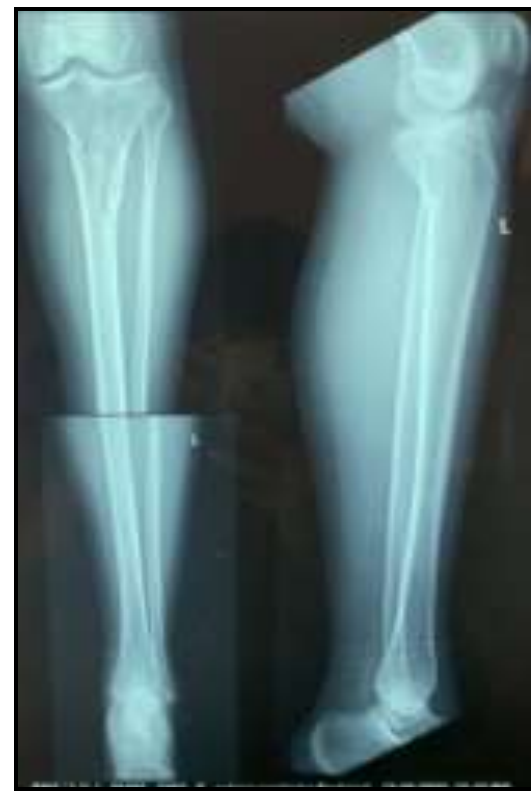

Pre-operative

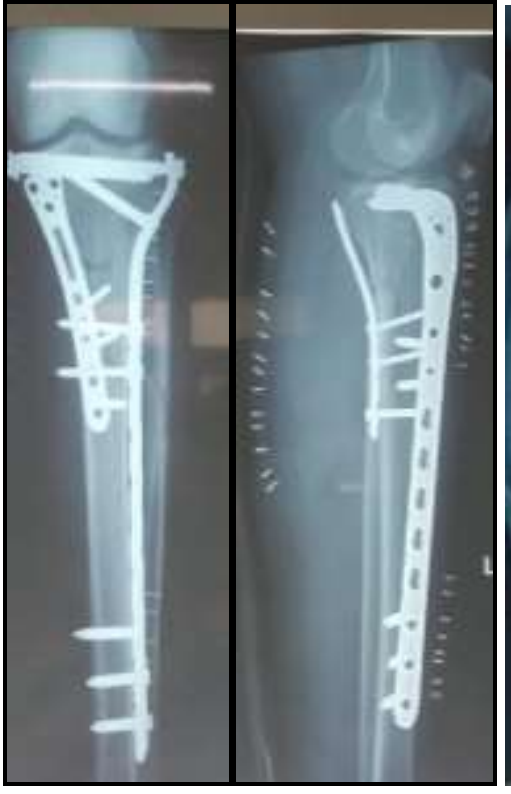

Postoperative

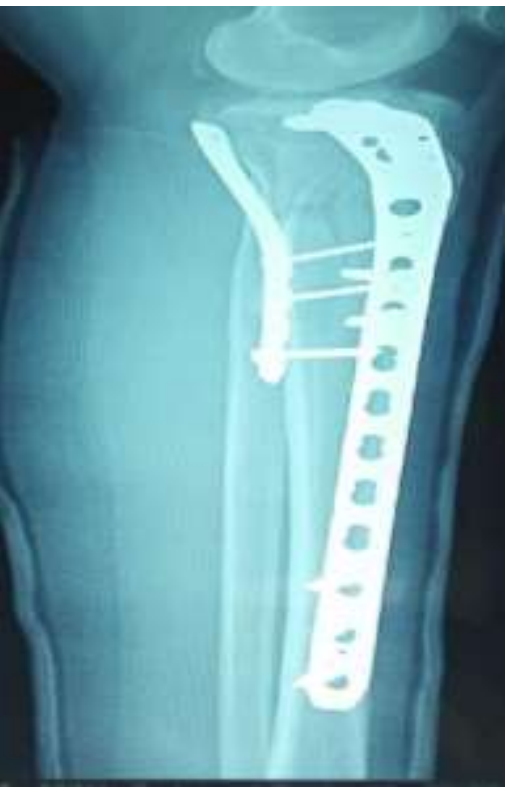

TWO months follow up

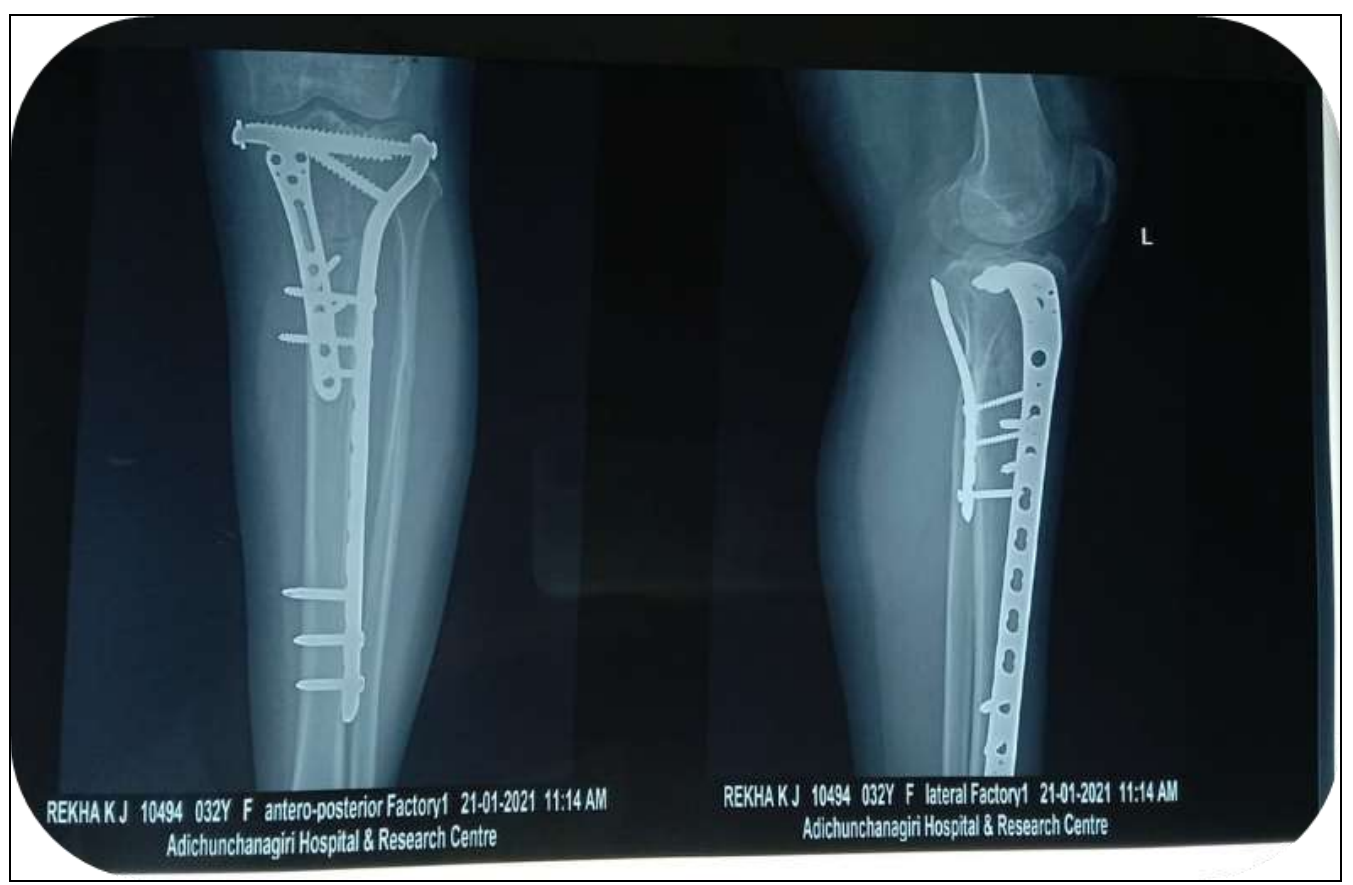

9 Months Follow Up X-Ray

\section{Outcome}

\section{HJ subjective score}

The symptoms analyzed include pain during activities, swelling, stiffness, weakness, limping, giving way, and crepitation. The worst grade in the seven symptoms was considered as the final outcome. A score of 1 to 5 was excellent; 6 to 10 good; 11 to 15 fair; and 16 to 25 poor. The subjective score in the study group was excellent for $80 \%$ of the patients. 16 patients were totally pain free during activities and 4 had mild pain. Of the 4 , two had a minimally displaced open fracture, one had a markedly displaced closed fracture, and the remaining ONE was minimally displaced closed fractures. All patients were free of swelling around the knee at follow up. Only two patients had mild stiffness around the knee. 18 patients did not feel any weakness at the knee. Two patients had mild weakness. 18 patients had excellent score for walking without limp. Two patients felt occasional giving way at the operated knee, which was of slight importance to him. 18 patients had an excellent score for crepitation around the knee. Only two patients gave importance to crepitation symptom at the knee.

\section{HJ Clinical Outcome}

The final clinical outcome score was good in 18 patients, fair in 3 patients, and poor in 1 patient. The clinical outcome score has 4 components: Extension lag, range of movement, thigh atrophy and stability at the knee. The worst score among the four was considered as the final outcome score.

None of the patients at follow up had an extension lag. The average knee flexion was $128.09^{\circ}$. The range of movement varied from $90^{\circ}$ to $145^{\circ}$. There were TWO patients with a flexion range of less than $110^{\circ}$. The average thigh atrophy in the operated side was $1.5 \mathrm{~cm}$ (range $1-4 \mathrm{~cm}$ ) as compared to the contralateral normal thigh. The stability at the knee was excellent in 18 patients. Two patients had mild anteromedial instability on clinical assessment, had a sense of occasional giving way at the knee on walking. 


\section{HJ Functional Outcome}

18 patients had excellent walking and 2 had good walking function (walking with slight limp). 18 patients had excellent stair climbing function and 2 had mild pain while climbing stairs. 15 patients had excellent squatting function and 4 had mild pain while squatting. 1 patient was unable to squat well. The poor squatting function in the 1 patient was due to poor knee range of movement and not due to pain. 14 patients had excellent jumping function. Excellent jumping meant that they were able to jump a distance similar to the uninjured leg, without pain. 6 patients could jump only $50-90 \%$ of the opposite normal side. Only 9 patients were able to do normal duck walking. 4 patients were able to duck walk a few steps. Two patients were able to duck walk one step. 5 patients were not able to duck walk.

\section{HJ Radiological Outcome}

Most patients had a "good" radiological score, with only two having a "fair" score. The criteria were extremely stringent. Differences of even 1 degree of plateau tilt from the opposite knee or $1 \mathrm{~mm}$ of articular step would classify the result as good and not excellent. A difference of more than 5 degree plateau tilt or a $3 \mathrm{~mm}$ articular step was a "fair" result. There were four components in the radiological score and the worst of them was shown as the final radiological score.

\section{Plateau tilt}

Sixteen patients had plateau tilt within 5 degrees from the opposite side and had scored good. Three patients had scored fair (mean tilt -7 degrees) and only one patient had scored poor with a tilt of 11 degrees. This patient had a markedly displaced closed fracture with a preoperative articular step of $10.54 \mathrm{~mm}$ and preoperative intercondylar widening of 13.34 $\mathrm{mm}$. The fracture was fixed using dual plates and postoperatively, there was no intercondylar widening or an articular step; but at years follow-up, there was 11 degrees varus tilt. This was because the posteromedial buttress plate did not provide adequate stability.

\section{Articular step}

Seventeen patients did not have any articular step at final follow up based on radiographs. The average pre-operative articular step was $5.34 \mathrm{~mm}$ (range $0-10.54 \mathrm{~mm}$ ). The average articular step postoperatively was $0.42 \mathrm{~mm}$ (range $0-2.74$ $\mathrm{mm}$ ). Three patients had a mild articular step postoperatively (1-3 mm).

\section{Condylar widening}

The average postoperative condylar widening was $3.17 \mathrm{~mm}$ (range $0-10 \mathrm{~mm}$ ). The average preoperative condylar widening was $6.19 \mathrm{~mm}$ (range 5-16.97 mm). Eight patients did not have any postoperative condylar widening. Ten patients scored good (within $5 \mathrm{~mm}$ ) and two patients scored poor with condylar widening of $10 \mathrm{~mm}$.

\section{Joint Space}

Eight patients did not have any decrease in joint space as compared to the uninjured knee in anteroposterior radiographs. In the remaining 12 patients, the joint space decrease was less than $50 \%$. The mean decrease in joint space was $10.23 \%$ at final follow up.

\section{Discussion}

High energy intra-articular fractures involving the tibial plateau are a challenge to orthopaedic surgeons. Road traffic accident is the most common cause of these fractures. In order to reconstruct the stable and painless mobile knee, still needs an expertise and sufficient technical knowledge. These fractures still are challenge for reduction in order to maintain the articular congruity, prevent varus collapse, and prevent the early onset of the secondary osteoarthritis in these complex tibial plateau fractures. Operative treatment remains the optimum treatment for early mobilization, various methods of fixation have been described like external fixation, hybrid fixator, plating through a single midline incision, plating using Mercedes Benz incision

A two incision double-plating technique is been recommended by the Association for Osteosynthesis/ Association for the Study of Internal Fixation for the treatment of bicondylar tibial plateau fractures ${ }^{[19]}$.

In our study males predominate the female with the ratio of $4: 1$, which shows the more active life style involving the high velocity injury.

Among 20 patients most common mode of injury being the road traffic accident, right side being more commonly involved than left side, we had 8 Schatzker type VI and 12 Schatzker V type, When AO classification was considered most common type was $\mathrm{AO} 41 \mathrm{C} 3$ followed by $\mathrm{AO} 41 \mathrm{C} 2$, and $\mathrm{AO} 41 \mathrm{C} 1$

Our study used Honkonen Jarvinen Criteria ${ }^{[25]}$ criteria for radiological, functional, clinical outcome which showed excellent to good result.

Our study reported Honkonen Jarvinen Clinical outcome to be $85 \%$ excellent, $12 \%$ good and $2 \%$ fair. The functional outcome was $80 \%$ excellent, $14 \%$ good, $4 \%$ fair and $2 \%$ poor. The Radiological outcome showed $79.28 \%$ excellent, $20.72 \%$ good, $0.70 \%$ fair results. Most common complication encountered in the study was the knee stiffness in 2 patients associated with poor compliance with protocols and follow up, further superficial wound infection noticed in one patient who were taken up for wound debridement. Skin necrosis was another complication noticed in 1 patient of our study which was dealt with regular saline dressing, skin grafting was done. One implant has been removed at the end of study with complete union, we noticed knee stiffness has predominately affects outcome than the wound infection or the skin necrosis. There was no cases of non-union and all fractures had either united or were uniting by the end of 1 year follow-up. There were also no cases of implant related failures like screw back out or implant breakage.

\section{Each technique has its own merits and demerits.}

The use of Isolated Lateral Locking plate and Dual Plates is still a ongoing debate. Patients treated with isolated lateral locking plate had high risk of loss of reduction and increased incidence of malunion [17] Lasanianos et al. showed that collapse of medial tibial plateau occurred in isolated lateral locking plate when he compared the biomechanical properties of intramedullary nail, dual plates and isolated lateral locking plates ${ }^{[18]}$ While Ilizarov fixation and Hybrid external fixation seems reasonable methods of fixation of these fractures, there are a few problems including the insufficient fracture reduction ${ }^{[19]}$ inconvenience of an external fixator that requires careful maintenance, possibility of pin tract infections, joint capsule penetration with resultant septic arthritis, subsequent collapse of fracture fragments ${ }^{[8]}$, and prolonged hospitalization ${ }^{[20]}$.

However they are useful in the treatment of open Schatzker type 5 and 6 tibial plateau fractures ${ }^{[18]}$ Though LISS (Less Invasive Stabilization System) permits in direct fracture 
reduction, fixed angle construct, percutaneous sub muscular implant, the cost is high and only case series has been published. Gosling et al. reported significant malreduction in 16 of 69 bicondylar fractures treated with LISS ${ }^{[19] .}$

Dual Plating is preferred over other techniques as it has several advantages:

- Better visualisation of fracture fragments, especially the posteromedial fragment and articular surface of proximal tibia ${ }^{[19]}$

- Dual incision reduces wound complications ${ }^{[19]}$

- Stability is achieved by fixing both the medial and the lateral columns.

- Interfragmentary compression will be achieved ${ }^{[17]}$.

- $\quad$ Rigid construct is achieved ${ }^{[17]}$.

Tul B Pun et al. in his study reported the outcome of 17 tibial plateau fractures. 9 of which were managed by dual plating and 8 managed by hybrid ex fix. Based on Honkonen Jarvinen Criteria all patients could walk, climb stairs, jump, $90 \%$ could squat, $50 \%$ could duck walk. $85 \%$ had plateau tilt $<5^{\circ}, 92 \%$ had articular step off $<2 \mathrm{~mm}$. No major infection ${ }^{[18]}$.

Ebrahim Ghayem Hassankhani et al. in his study reported 22 patients with tibial plateau fractures treated with dual plating. The outcome was assessed based on knee society score. 86 . $4 \%$ had excellent, 9. 1\% had good, 4. 5\% had fair and no one showed poor results ${ }^{[20]}$.

Yong Zang et al. in his study reported 41 patients fixed with double buttress plate and 38 patients fixed with lateral locking plate and buttress plate. The mean Hospital for Special Surgery Score was 77. $9 \pm 9.4$ and $79 \pm 7.9$ Respectively ${ }^{[19]}$. Chang Wug Oh et al. in his study reported 23 unstable proximal tibia fractures treated with double plating [21]. patients had excellent and radiographic results, 1 patient had shortening $(1 \mathrm{~cm}), 2$ cases had mild varus malalignment $\left(<10^{\circ}\right), 1$ case had superficial infection which improved with implant removal, no deep infection occurred ${ }^{[21]}$.

G. Thiruvengita Prasad et al in his study reported 40 patients fixed with double plating and based on oxford knee society score 30 patients had excellent and 10 patients had good outcome respectively ${ }^{[3]}$

David P. Barei et al. in the year 2006 in there study of 83 patients showed, the patients with very high velocity injury to proximal tibia can still have satisfactory articular reduction with dual plating ${ }^{[2]}$.

Neogi et al. in their study have shown that the dual plating for bicondylartibial fracture has better outcome than a single lateral locking plate as dual plating gives better anatomical reduction of the proximal tibia ${ }^{[22]}$.

Niel Rohra et al. in 2013 showed excellent to good functional outcome with minimal soft tissue complications with dual plating of tibial bicondylar fractures. They also show that fixation done by dual plating helps in early mobilisation of the knee joint in there fractures ${ }^{[23]}$.

\section{Conclusion}

1. From our study we conclude that High velocity tibial plateau fracturs (type V and type VI schatzkers) have excellent to good clinical, functional and radiological outcome.

2. Early mobilisation of the knee joint post operatively provides good range of motion.

3. Posteromedial plating provides a buttress to posteromedial fragment and thereby prevents varus collapse.

4. The patients with good soft tissue coverage should undergo anatomical reduction and rigid fixation with plating immediately without deferring time.

5. This is a short term study and need long term follow up to predict the further outcome

\section{References}

1. Marsh JL, Karam DM. Tibial plateau fractures. Chapter 55. In: Rockwood, Green (eds.), Fracture in adults. $8^{\text {th }}$ ed. London: Wolters Kluwer Health 2015.

2. Barei PD, Nork ES, Mills JW, Coles PC, Henley MB, Benirschke KS. Functional outcomes of severe bicondylar tibial plateau fractures treated with dual incisions and medial and lateral plates. Journal of Bone and Joint Surgery 2006;88-a:8.

3. Prasad GT, Kumar TS, Kumar RK, Murthy KG, Sundaram N. Functional outcome of Schatzker type V and VI tibial plateau fractures treated with dual plates Indian Journal of Orthopaedics 2013;47:2.

4. Mankin HJ. The response of articular cartilage to the mechanical injury. J Bone Joint Surg 1982;64A:460-6.

5. Girgis FG, Marshal JL, Onajen ARS. The cruciate ligaments of the knee joints: Anotomical, functional and experimental analysis. Clin Orthop 1975;106:216-31.

6. Miller DM. Review of orthopaedics. Basic Science. 1992;1:42.

7. Thomas A, Athanasiov M, Scheutz MW. Current concepts in tibial plateau fractures. Acta Chir Orthop Traumatol Cech 2009;76(5):363-73.

8. Egol KA, Su E, Tejwani NC, Sims SH, Kummer FJ, Koval KJ. Treatment of complex tibia plateau fractures using less invasive stabilization system plate. J Trauma. 2004;57:340-6.

9. DeCoster TA, Nepola JV, el-Khoury GY. Treatment of proximal tibia fracture: A ten year follow up study. Clin Orthop Relat Res 1988;196-204.

10. Mazone CG, Guanche CA, Vrahas MS. Arthroscopic management of tibia plateau fractures. Am J Orthop. 1999;28:508-15.

11. Mills WJ, Work SE. Open reduction and internal fixation of high energy tibial plateau fractures. Orthop Clin North Am 2002;33(IX):177-98.

12. Fulkerson E, Egol KA, Kubiak EN, Liporace F, Kummer FJ, Koval KJ. Fixation of diaphyseal fractures with a segmental defect a biomechanical comparison of locked and conventional plate techniques. J Trauma. 2006;60(4):830-5.

13. Messmer P, Regazzoni P, Gross T. New stabilization technique for fixation of proximal tibia fractures (LISS/LCP).The Umsch 2007;60:762-7.

14. Wagner M. General principles for the clinical use of the LCP. Injury 2003;34(2):B31-42.

15. Schatzker J. Fractures of the Tibial Plateau. Chapter 19. In: Schatzker J, Tile M (eds.), The Rationale of Operative Fracture Care. New York: Springer, 2005, 447-69.

16. Rudloff IM. Fractures of the Lower Extremity. In: Campbell's Operative Orthopaedics Philadelphia: Elsevier 2013, 2668-274.

17. Pelsar PM. Controversies in the management of tibial plateau fractures. SA Orthop J 2010;9(3):75.

18. Pun TB. Outcome of Schtazker's type 5 and type 6 fractures. Indian Journal of Orthopaedics 2014;48:1.

19. Zhang Y. Treatment of Complicated Tibial Plateau fractures with Dual Plating via 2 incision technique. Orthosupersite.com 2012;35:3.

20. Hassankhani EG. Treatment of Complex Proximal Tibial 
fractures (Type $5 \& 6$ Schatzker Classification) by Double Plate fixation with Single Anterior Incision. Open Journal of Orthopaedics 2013;3:208-212.

21. Oh CW. Double plating of unstable proximal tibial fractures using minimally invasive percutaneous osteosynthesis technique. Acta Orthopaedia. 2006;77(3):524-30.

22. Neogi DS, Trikha V, Mishra KK, Bandekar MS, Yadav CS. Comparative study of single lateral locked plating versus double plating in type $\mathrm{C}$ bicondylar tibial plateau fractures. Indian Journal of Orthopaedics 2015;49:2.

23. Rohra N, Suri HS, Gangrade K. Functional and radiological outcome of Schatzker type $\mathrm{v}$ and vi tibial plateau fracture treatment with dual plates with minimum 3 years follow-up: A prospective study. Journal of Clinical and Diagnostic Research 2016;10(5):RC05RC10.

24. Eggli S, Hartel MJ, Kohl S, Haupt U, Exadaktylos AK, Roder C. Unstable bicondylar tibial plateau fractures: A clinical investigation. J Orthop Trauma 2008;22:673-9.

25. Honkonen SE, Jarvinen MJ. Classification of fractures of the tibial condyles. J Bone Joint Surg Br 1992;74:840-7. 